\title{
Efeito da temperatura de queima em algumas propriedades mecânicas de cerâmica vermelha
}

\section{(Effect of the firing temperature on some mechanical properties of red ceramic)}

\author{
B. C. A. Pinheiro, J. N. F. Holanda \\ Universidade Estadual do Norte Fluminense, CCT-LAMAV, Grupo de Materiais Cerâmicos, Av. Alberto Lamego \\ 2000, Campos dos Goytacazes, RJ 28013-602 \\ holanda@uenf.br
}

\begin{abstract}
Resumo
O objetivo deste trabalho foi avaliar algumas propriedades mecânicas de cerâmica vermelha como uma função da temperatura de queima. A massa argilosa usada foi caracterizada por meio da determinação da composição química, difração de raios X, distribuição do tamanho de partícula, morfologia, plasticidade e comportamento dilatométrico. Foram conformadas peças cerâmicas por prensagem uniaxial e queimadas a $850{ }^{\circ} \mathrm{C}, 950{ }^{\circ} \mathrm{C}$ e $1050{ }^{\circ} \mathrm{C}$. As peças queimadas foram avaliadas em termos de tensão de ruptura a flexão, módulo de elasticidade flexural, parâmetro de Weibull, tensão característica, massa específica aparente, absorção de água e área superficial específica. A evolução da microestrutura foi acompanhada via microscopia eletrônica de varredura e difração de raios X. Os resultados mostram que a temperatura de queima influencia diretamente nas propriedades mecânicas de cerâmica vermelha. Uma quantidade significativa de poros abertos foi eliminada, principalmente para temperaturas acima de 950 ${ }^{\circ} \mathrm{C}$. Os dados de tensão de ruptura a flexão resultaram em distribuição de Weibull, cujos parâmetros de Weibull estão compreendidos na faixa $8,59-12,42$.
\end{abstract}

Palavras-chave: cerâmica vermelha, propriedades mecânicas, porosidade.

\begin{abstract}
The aim of this work was to evaluate some mechanical properties of red ceramic as a function of the firing temperature. The clayey mass was characterized in terms of chemical composition, X-ray diffraction, particle size distribution, morphology, plasticity, and dilatometric behavior. Test specimens were prepared by uniaxial pressing and fired at $850{ }^{\circ} \mathrm{C}, 950{ }^{\circ} \mathrm{C}$, and $1050^{\circ} \mathrm{C}$. Fired test specimens were characterized in terms of flexural strength, elastic modulus, Weibull parameter, characteristic strength, apparent density, water absorption, and specific surface area. The microstructural evolution was accompanied by scanning electron microscopy and $X$-ray diffraction. The results showed that the firing temperature directly influenced in the mechanical properties of red ceramic. A high content of open pores was eliminated mainly above $950{ }^{\circ} \mathrm{C}$. The flexural strength test data resulted in Weibull distributions, whose Weibull parameters are in the range 8.59-12.42.
\end{abstract}

Keywords: red ceramic, mechanical properties, porosity.

\section{INTRODUÇÃO}

O setor de cerâmica vermelha se caracteriza pela cor avermelhada de seus produtos, que são tijolos maciços, blocos cerâmicos (vedação e estrutural), telhas, tubos, lajes para forro, vasos ornamentais, agregados leve de argila expandida, etc [1]. No Brasil existem cerca de 14.000 empresas de cerâmica vermelha espalhada por todo território nacional, sendo que a maioria das empresas é de pequeno e médio porte. As empresas de cerâmica vermelha utilizam matérias-primas argilosas naturais, as quais estão sujeitas a larga variabilidade de suas propriedades.

Existe extensa literatura sobre as características e propriedades tecnológicas de argilas brasileiras usadas na fabricação de cerâmica vermelha [2-17]. Verifica-se que na maioria dos trabalhos se busca basicamente determinar se uma determinada matéria-prima argilosa está apta ou não para fabricação de cerâmica vermelha para construção civil. Em particular, as propriedades mecânicas de cerâmica vermelha têm sido pouco estudadas. Este fato é importante tendo em vista que um percentual significativo dos produtos de cerâmica vermelha para construção civil fabricados no Brasil, via de regra apresentam valores de resistência mecânica inferiores aos recomendados pelas normas técnicas.

No processo de fabricação de cerâmica vermelha são utilizadas basicamente argilas comuns. Essas argilas apresentam larga variabilidade em termos de composição química, mineralógica e física [18]. Em geral essas argilas puras não apresentam condições favoráveis de 
processamento. Por esse motivo, as massas argilosas industriais para cerâmica vermelha são formuladas usando dois ou mais tipos de argilas comuns, no sentido de propiciar condições favoráveis de conformação e propriedades finais [19].

As propriedades mecânicas dos produtos de cerâmica vermelha são dependentes da composição das argilas e das condições de processamento empregados. Em particular a temperatura de queima é um parâmetro de processamento que influencia fortemente as propriedades mecânicas. A maioria das empresas de cerâmica vermelha no Brasil não utiliza uma temperatura de queima adequada na fabricação de seus produtos, o qual resulta em produtos de baixa qualidade. Por outro lado, durante o processo de queima um conjunto bastante complexo de reações físico-químicas, dependentes da temperatura de queima, se processam no interior da massa cerâmica argilosa [18]. Essas reações promovem a formação de novas fases cerâmicas, que são determinantes para as propriedades físico-mecânicas no produto final. A temperatura de queima se constitui na atualidade também em um importante parâmetro tecnológico na indústria de cerâmica vermelha, com implicações econômicas, energéticas e ambientais.

O objetivo principal deste trabalho é estudar o efeito da temperatura de queima sobre algumas propriedades mecânicas de cerâmica vermelha para construção civil. Ênfase especial é dada à correlação entre temperatura de queima, microestrutura, porosidade e propriedades mecânicas.

\section{MATERIAIS E MÉTODOS}

Foi utilizada uma massa argilosa industrial coletada de uma empresa de cerâmica vermelha instalada na região de Campos dos Goytacazes, RJ. A massa argilosa foi cominuída e classificada por peneiramento para a fração < 40 mesh $(425 \mu \mathrm{m})$.

A análise mineralógica da massa argilosa foi feita por difração de raios X em difratômetro Seifert URD65, com radiação $\mathrm{Cu}-\mathrm{k} \alpha$, sob ângulo $2 \theta$ de $3^{\circ}$ até $45^{\circ}$. A composição química foi determinada por espectrofotometria de emissão atômica com plasma indutivamente acoplado. A distribuição de tamanho de partículas foi determinada por meio de uma combinação de peneiramento e sedimentação. A morfologia das partículas foi examinada em um microscópio eletrônico de varredura Zeiss DSM 962 operando em $15 \mathrm{kV}$. A plasticidade da massa argilosa foi determinada via método de Atterberg usando procedimentos padronizados. $\mathrm{O}$ ensaio de análise dilatométrica foi realizado em um dilatômetro BP Engenharia RB-115 com taxa de aquecimento $5{ }^{\circ} \mathrm{C} / \mathrm{min}$.

A massa argilosa preparada foi submetida à secagem em $110{ }^{\circ} \mathrm{C}$ por $24 \mathrm{~h}$, seguida de umidificação até $7 \%$ e mantida em saco plástico fechado num dessecador durante $24 \mathrm{~h}$. As peças cerâmicas foram conformadas por prensagem uniaxial numa prensa hidráulica a $24 \mathrm{MPa}$ com uma matriz de aço com cavidade retangular $\left(11,50 \times 2,54 \mathrm{~cm}^{2}\right)$. Após compactação, as peças cerâmicas foram secadas a $110^{\circ} \mathrm{C}$ até peso constante. O processo de queima das peças cerâmicas foi feito num forno elétrico tipo mufla. Neste trabalho foi usado um ciclo de queima lento ( $24 \mathrm{~h}$ frio a frio), cujas temperaturas máximas de patamar foram $850{ }^{\circ} \mathrm{C}, 950{ }^{\circ} \mathrm{C}$ e $1050{ }^{\circ} \mathrm{C}$. Estas temperaturas estão dentro da faixa de queima industrial de cerâmica vermelha [20].

A identificação das fases cristalinas das peças de cerâmica vermelha queimadas foi feita por difração de raios X. A microestrutura da superfície de fratura das peças cerâmicas foi observada via imagens de elétrons secundários, em um microscópio eletrônico de varredura Zeiss DSM 962 operando em $15 \mathrm{kV}$. A área superficial específica das peças queimadas foi determinada em um equipamento Autosorb-1 Quantachrome Instr. ASIC-VPL. Além disso, a massa específica aparente e a absorção de água das peças foram determinadas de acordo com procedimentos padronizados.

As peças cerâmicas foram submetidas a ensaios de flexão em carregamento de três pontos em uma máquina de ensaios universal Instron 5582, capacidade $100 \mathrm{kN}$. A carga foi aplicada pelo cutelo superior numa velocidade de $0,5 \mathrm{~mm} /$ min até a ruptura da peça cerâmica. A tensão de ruptura à flexão $\sigma$ foi então determinada de acordo com a seguinte expressão:

$$
\sigma=\left(3 \text { P.L } / 2 \text { b.d } \text { d }^{2}\right)
$$

onde P é a carga de ruptura (N), L é a distância entre os cutelos que no presente trabalho foi de $96 \mathrm{~mm}$, b é a largura da peça cerâmica $(\mathrm{mm})$ e d é espessura do peça cerâmica $(\mathrm{mm})$.

Os dados de tensão de ruptura à flexão obtidos foram tratados estatisticamente por meio da estatística de Weibull $[21,22]$, que é fundamentada no modelo do elo mais fraco. $\mathrm{O}$ tamanho da amostra usado foi $\mathrm{N}=30$. A probabilidade de fratura $\mathrm{F}$ foi determinada de acordo com o método de distribuição acumulada de amostras simétricas, usando o estimador de probabilidade $\mathrm{F}=(\mathrm{i}-0,5) / \mathrm{N}$.

$\mathrm{O}$ módulo de elasticidade flexural $\mathrm{E}$ das peças cerâmicas foi determinado utilizando-se a expressão da flecha para uma viga bi-apoiada [23]:

$$
\mathrm{E}=\left(\mathrm{P} . \mathrm{L}^{3} / 48 \mathrm{I} . \delta\right)
$$

onde I é o momento de inércia $\left(\mathrm{mm}^{4}\right)$ e $\delta$ é a flecha (mm).

\section{RESULTADOS E DISCUSSÃO}

A Fig. 1 apresenta o difratograma de raios X para a massa argilosa utilizada neste trabalho. Pode-se observar uma presença predominante de picos de difração característicos da caulinita, além da presença do quartzo e gibsita. Há ainda indícios de illita/mica, feldspato potássico e goetita. A composição química da massa argilosa é apresentada na Tabela I. Verifica-se uma composição típica de argila sedimentar para cerâmica vermelha, com predominância de $\mathrm{SiO}_{2}, \mathrm{Al}_{2} \mathrm{O}_{3}$ e $\mathrm{Fe}_{2} \mathrm{O}_{3}$. Nota-se um alto percentual de $\mathrm{Al}_{2} \mathrm{O}_{3}$, que tende a aumentar a refratariedade da massa argilosa. 
Já o alto teor de $\mathrm{Fe}_{2} \mathrm{O}_{3}$ caracteriza uma massa argilosa que queima tipicamente na cor avermelhada. A massa argilosa apresentou a seguinte distribuição de tamanho de partículas: $<2 \mu \mathrm{m}=43 \%, 2-20 \mu \mathrm{m}=25 \%$ e $>20 \mu \mathrm{m}=32 \%$. De acordo com o diagrama de Winkler [24], a massa argilosa estudada apresenta uma distribuição de tamanho de partículas (dosagem de partículas finas, médias e grossas) dentro da faixa adequada para fabricação de telhas de alta qualidade. A morfologia das partículas do pó argiloso é apresentada na Fig. 2. As partículas apresentam-se aglomeradas e em forma de placas finas de perfil irregular, provavelmente do argilomineral caulinita. $\mathrm{O}$ índice de plasticidade obtido foi $26 \%$, que está dentro da faixa adequada para fabricação de cerâmica vermelha [20].

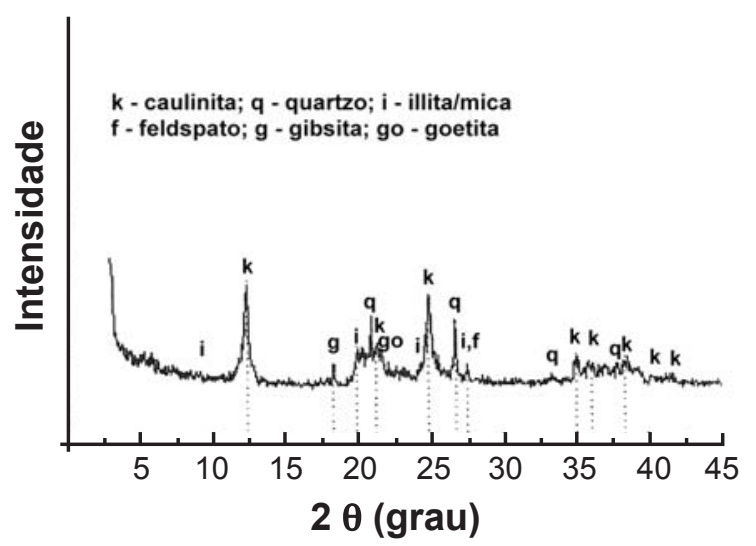

Figura 1: Difratograma de raios $\mathrm{X}$ da massa argilosa. [Figure 1: X-ray diffraction pattern of the clayey mass.]

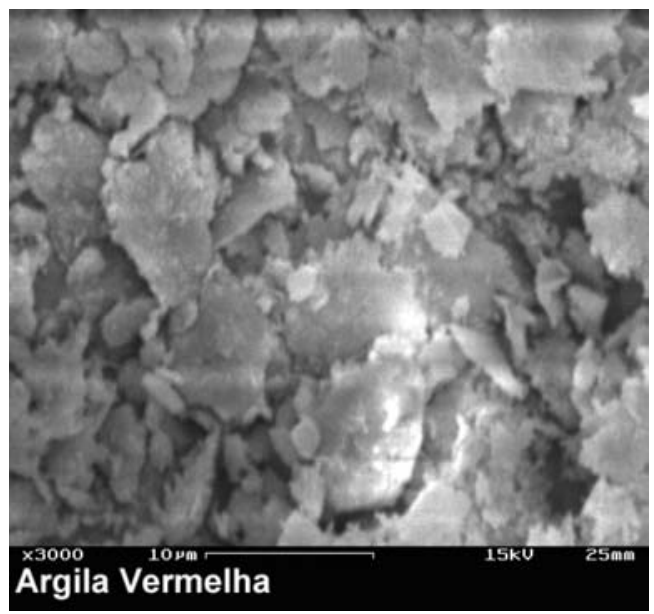

Figura 2: Morfologia das partículas da massa argilosa. [Figure 2: Morphology of the particles of clayey mass.]

Os difratogramas de raios $\mathrm{X}$ das peças cerâmicas queimadas entre 850 e $1050{ }^{\circ} \mathrm{C}$ são apresentados na Fig. 3. As peças de cerâmica vermelha ricas em caulinita apresentaram importantes transformações de fases durante o processo de queima. Estes processos tendem a influenciar a densificação e propriedades físico-mecânicas de cerâmica vermelha. Em $850^{\circ} \mathrm{C}$ os picos da caulinita e gibsita não estão presentes, mas aqueles referentes à illita/mica, feldspato
Tabela I - Composição química da massa argilosa (\% em peso).

[Table I - Chemical composition of the clayey mass (wt.\%)].

\begin{tabular}{cc}
\hline $\mathrm{SiO}_{2}$ & 41,90 \\
$\mathrm{Al}_{2} \mathrm{O}_{3}$ & 32,52 \\
$\mathrm{Fe}_{2} \mathrm{O}_{3}$ & 9,29 \\
$\mathrm{TiO}_{2}$ & 1,20 \\
$\mathrm{MnO}$ & 0,04 \\
$\mathrm{MgO}$ & 0,87 \\
$\mathrm{CaO}$ & 0,18 \\
$\mathrm{~K} 2 \mathrm{O}$ & 1,55 \\
$\mathrm{Na} O$ & 0,39 \\
$\mathrm{PF}$ & 12,06 \\
\hline
\end{tabular}

e quartzo permanecem. A caulinita $\left(\mathrm{Al}_{2} \mathrm{O}_{3} \cdot 2 \mathrm{SiO}_{2} \cdot 2 \mathrm{H}_{2} \mathrm{O}\right)$ sofreu desidroxilação em torno de $450-600{ }^{\circ} \mathrm{C}$ [18] com remoção dos grupos $\mathrm{OH}^{-}$da rede cristalina. Isto resulta na formação da metacaulinita amorfa $\left(\mathrm{Al}_{2} \mathrm{O}_{3} \cdot 2 \mathrm{SiO}_{2}\right)$. A gibsita foi transformada para uma alumina de transição. Quando a temperatura de queima é elevada até $950{ }^{\circ} \mathrm{C}$, os picos de mullita primária e/ou de uma fase tipo espinélio $\mathrm{Al}: \mathrm{Si}$ aparecem. Estas fases são desenvolvidas a partir da metacaulinita via reações topotáticas [18]. Acima de $950{ }^{\circ} \mathrm{C}$ os picos de illita/mica e feldspato desaparecem, mas aqueles referentes à mullita primária, espinélio $\mathrm{Al}: \mathrm{Si}$ e quartzo permanecem. Observa-se que em $1050{ }^{\circ} \mathrm{C}$ há indícios da presença da cristobalita. Nota-se ainda a presença de hematita em todas as temperaturas de queima.

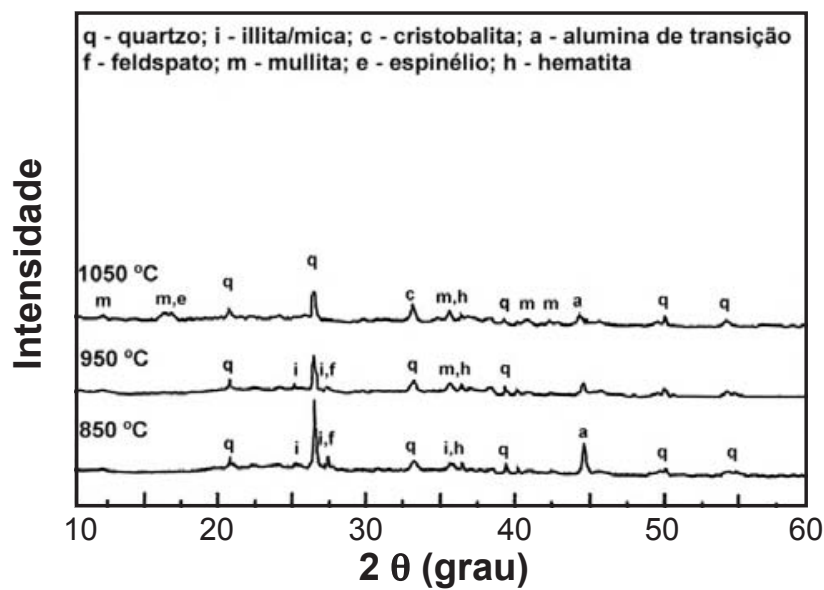

Figura 3: Difratogramas de raios $\mathrm{X}$ das peças de cerâmica vermelha em diferentes temperaturas.

[Figure 3: X-ray diffraction patterns for the red ceramic pieces at different temperatures.]

O comportamento dilatométrico da massa cerâmica argilosa é apresentado na Fig. 4. Pode-se observar um comportamento típico de material caulinítico [25]. A massa argilosa rica em caulinita apresenta uma pequena dilatação até cerca de $500{ }^{\circ} \mathrm{C}$, seguido de três retrações. A dilatação observada se deve fundamentalmente a expansão térmica que os materiais sofrem quando aquecidos. A primeira 
retração observada por volta de $500-650{ }^{\circ} \mathrm{C}$ ocorre de forma brusca, devido principalmente à aproximação das partículas pela perda de água de constituição da caulinita e concomitante formação da metacaulinita. A segunda retração por volta de $700-850{ }^{\circ} \mathrm{C}$ ocorre de forma menos intensa e pode ser atribuída ao início da sinterização do pó argiloso. A terceira retração por volta de $900-1000{ }^{\circ} \mathrm{C}$ ocorre de forma brusca, que pode ser atribuída à recristalização de novas fases cerâmicas e concomitante início da vitrificação da massa argilosa.

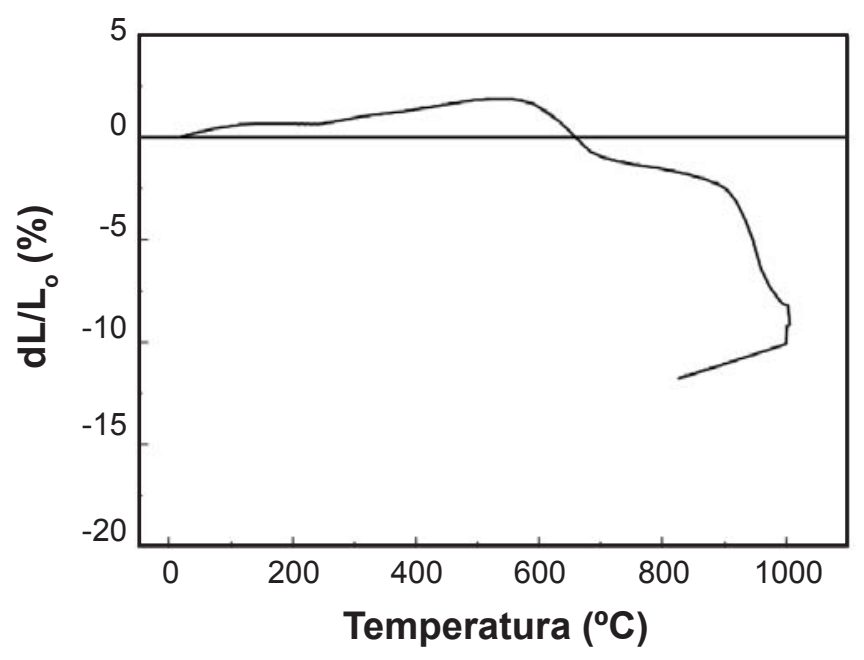

Figura 4: Análise dilatométrica da massa argilosa.

[Figure 4: Dilatometric analysis of the clayey mass.]

A Fig. 5 apresenta a evolução microestrutural da superfície de fratura em função da temperatura de queima para as peças de cerâmica vermelha. Em $850{ }^{\circ} \mathrm{C}$ (Fig. 5a) a superfície de fratura é muito rugosa e a estrutura é notadamente porosa. Fica evidente a presença de um grande volume de poros abertos na forma de vazios interpartículas na estrutura. Os poros apresentam morfologia irregular típica do estágio inicial de sinterização. As placas de metacaulinita amorfa que são fracamente ligadas durante o processo de queima podem ser observadas. Quando a temperatura é elevada até $950{ }^{\circ} \mathrm{C}$ (Fig. 5b), não ocorrem grandes modificações na estrutura da cerâmica vermelha. Nesta temperatura ainda está presente um grande volume de poros abertos. Com a elevação da temperatura até $1050{ }^{\circ} \mathrm{C}$ (Fig. 5c), a peça de cerâmica vermelha apresenta uma superfície de fratura com textura mais suave e menos porosa. $\mathrm{O}$ volume de poros abertos diminuiu significativamente. $\mathrm{O}$ crescimento de pescoço interpartícula e a formação de uma fase líquida são os principais responsáveis pela eliminação de grande quantidade de porosidade aberta no interior da peça de cerâmica vermelha. A rigor a fase líquida quando resfriada se transforma em filamentos finos de vidro que tende a preencher parcialmente os poros abertos na estrutura da peça cerâmica.

A massa específica aparente e a área superficial específica das peças de cerâmica vermelha são apresentadas na Fig. 6. O efeito da temperatura de queima foi o de promover o
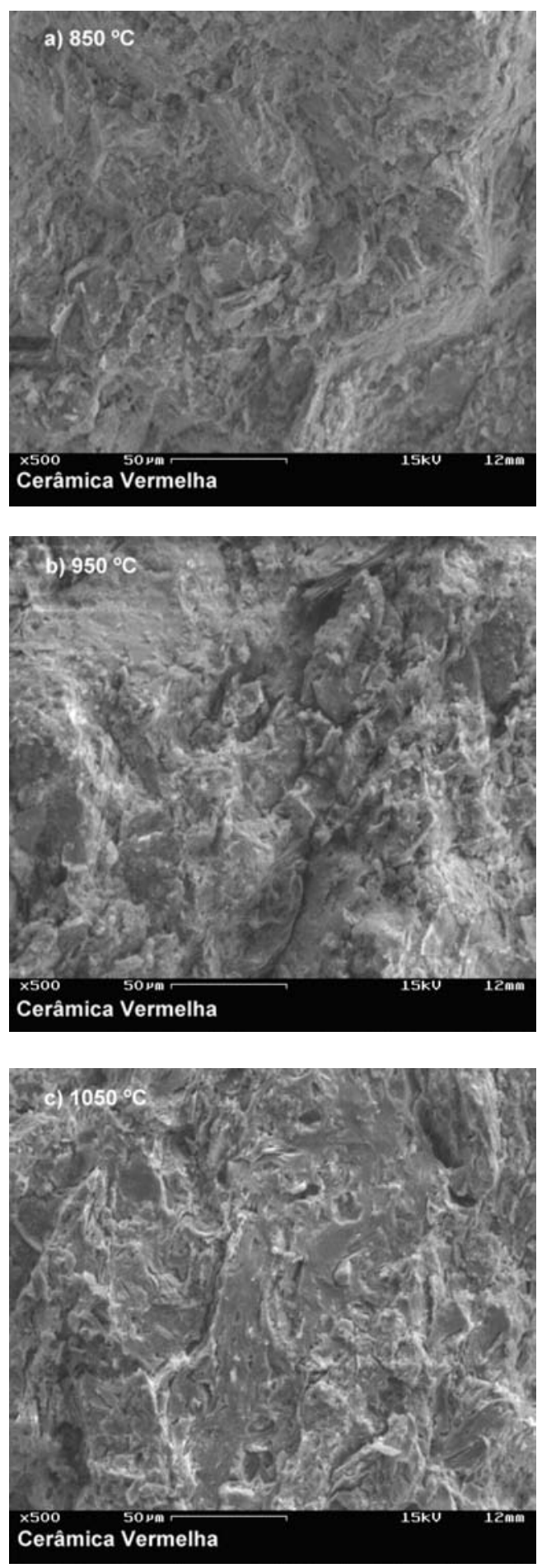

Figura 5: Micrografias obtidas por microscopia eletrônica de varredura das peças de cerâmica vermelha: a) $850{ }^{\circ} \mathrm{C}$; b) $950{ }^{\circ} \mathrm{C}$; e c) $1050{ }^{\circ} \mathrm{C}$.

[Figure 5: SEM micrographs of the red ceramic pieces: a) $850{ }^{\circ} \mathrm{C}$; b) $950{ }^{\circ} \mathrm{C}$; and c) $1050^{\circ} \mathrm{C}$.]

aumento da densificação com concomitante redução da área superficial específica. Isto é importante por a redução de área superficial atuar como a força motora principal durante o processo de sinterização. Este comportamento corrobora 
as estruturas observadas durante o processo de queima. Além disso, está de acordo com a composição de fases (Fig. 3) e comportamento dilatométrico (Fig. 4) das peças de cerâmica vermelha. Do ponto de vista prático em se tratando de cerâmica vermelha os resultados da microestrutura são interessantes. Para temperaturas de queima até cerca de $950{ }^{\circ} \mathrm{C}$ obtém-se uma microestrutura porosa mais favorável à fabricação de tijolos e blocos cerâmicos. Estes produtos por natureza devem ser notadamente mais porosos, para que eles possam ser usados no processo construtivo de forma adequada. Enquanto que para temperaturas de queima acima de $950{ }^{\circ} \mathrm{C}$ obtém-se uma microestrutura suave e mais densa, que favorece a produção de telhas e tubos. Nestes produtos, por exemplo, uma importante propriedade técnica é a impermeabilidade, que exige uma microestrutura notadamente mais densa.

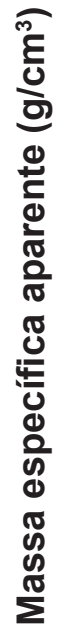

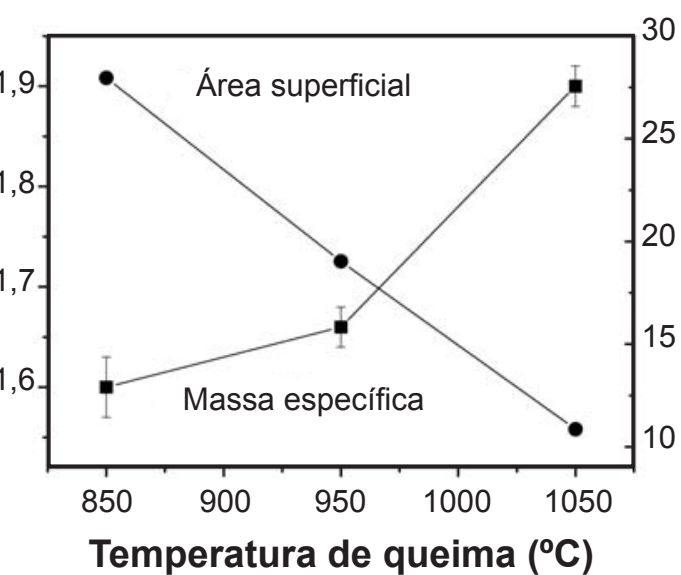

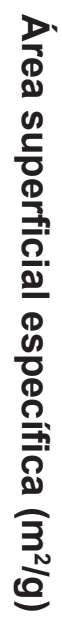

Figura 6: Massa específica aparente e área superficial específica em função da temperatura de queima.

[Figure 6: Apparent density and specific surface area as a function of the firing temperature.]

A Fig. 7 apresenta os valores de tensão de ruptura à flexão e absorção de água em função da temperatura de queima. Pode-se observar o aumento da resistência mecânica com concomitante redução da absorção de água (porosidade aberta) com o aumento da temperatura de queima. Isto indica que a razão principal para o aumento da resistência mecânica em cerâmica vermelha é a redução da porosidade aberta no interior da peça cerâmica. De forma que dependendo da tipologia de produto de cerâmica vermelha a ser fabricado há necessidade do controle do nível de porosidade aberta. O efeito deletério da porosidade aberta sobre a resistência mecânica está fundamentalmente relacionado aos seguintes fatores: i) os poros reduzem a área da seção cruzada na qual a carga é aplicada; e ii) os poros atuam como concentradores de tensão.

A Fig. 8 apresenta o diagrama de Weibull $(\ln \ln [1 /(1-\mathrm{F})]$ versus $\ln \sigma$ ) para as peças de cerâmica vermelha queimadas em $950^{\circ} \mathrm{C}$. A partir de análise por regressão linear dos pontos experimentais foram determinados o parâmetro de Weibull

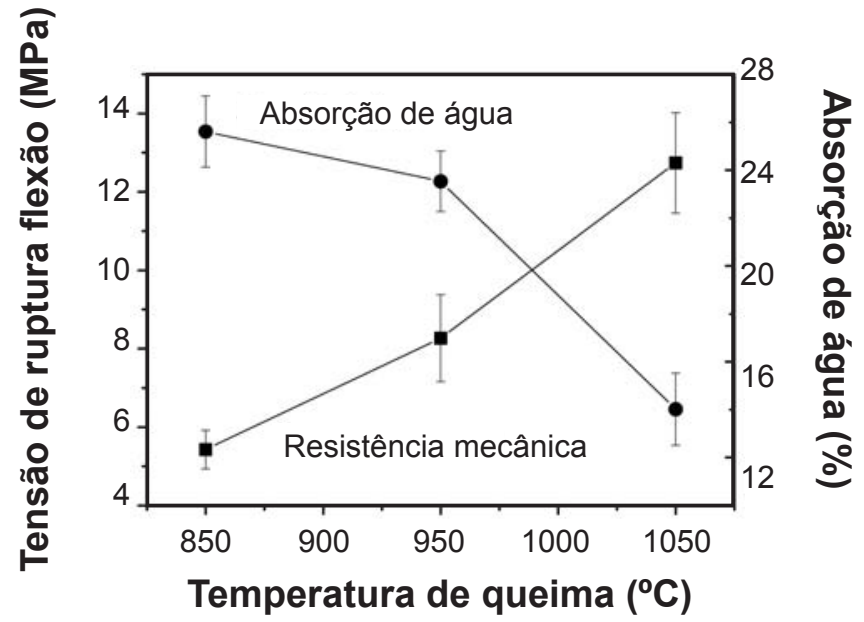

Figura 7: Tensão de ruptura à flexão e absorção de água em função da temperatura de queima.

[Figure 7: Flexural strength and water absorption as a function of the firing temperature.]

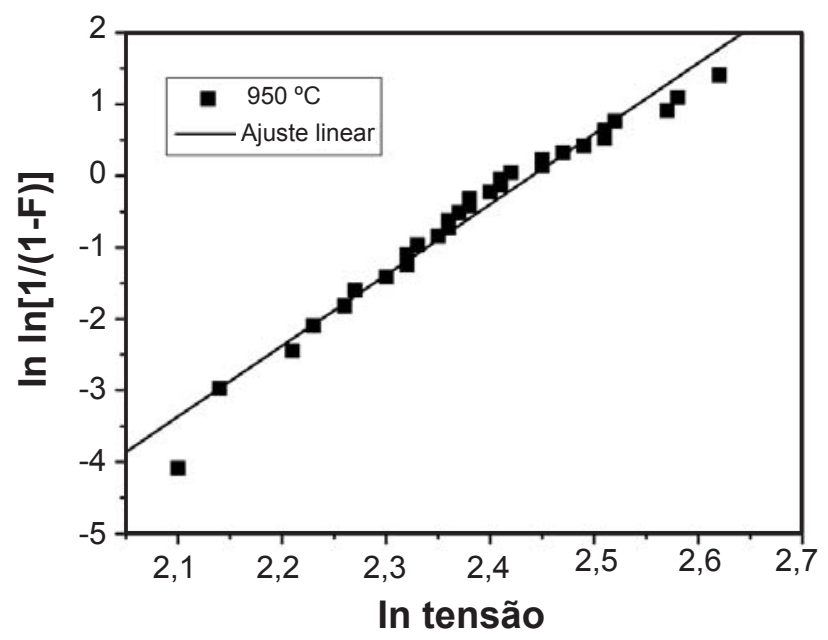

Figura 8: Diagrama de Weibull para cerâmica vermelha queimada em $950^{\circ} \mathrm{C}$.

[Figure 8: Weibull diagram for red ceramic fired at $950^{\circ} \mathrm{C}$.]

(m) e a tensão característica $\left(\sigma_{\mathrm{o}}\right)$. O parâmetro de Weibull é considerado como sendo uma espécie de risco de ruptura, além de ser aditivo e um critério importante na confiabilidade de materiais cerâmicos. A rigor o parâmetro de Weibull caracteriza o espalhamento dos dados de resistência mecânica das peças de cerâmica vermelha. A tensão característica é um parâmetro de localização, na qual a probabilidade de falha é de $63,2 \%$ [22]. Na Tabela II são apresentados os valores do parâmetro de Weibull, tensão característica e coeficiente de correlação (R) para todas as peças de cerâmica vermelha queimadas entre 850 e $1050{ }^{\circ} \mathrm{C}$. Verifica-se que os valores de coeficiente de correlação são próximos de 1. Isto indica que os dados experimentais de tensão de ruptura para a cerâmica vermelha estudada são ajustados conforme a teoria de Weibull.

Nota-se ainda na Fig. 8 que as peças de cerâmica vermelha queimadas na temperatura de $950{ }^{\circ} \mathrm{C}$ apresentaram um comportamento unimodal. Este comportamento foi também 
observado para as demais temperaturas de queima. Isto é importante por significar que as peças de cerâmica vermelha estudadas apresentam uma mesma classe de defeitos responsáveis pela sua fratura. Neste caso, como observado na microestrutura da superfície de fratura (Fig. 5), provavelmente são os poros abertos os defeitos responsáveis pela fratura das peças de cerâmica vermelha. A tensão característica das peças cerâmicas aumenta com o aumento da temperatura de queima. Isto está de acordo com a tensão de ruptura à flexão (Fig. 7), o qual se deve fundamentalmente a maior densificação das peças cerâmicas. Os valores de parâmetro de Weibull obtidos estão compreendidos na faixa $8,59-12,42$. Estes valores se situam dentro da faixa para materiais cerâmicos $(3<\mathrm{m}<15)$ [26]. Por outro lado, observa-se que o efeito da temperatura de queima foi o de reduzir o parâmetro de Weibull, a despeito de se aumentar a resistência mecânica das peças de cerâmica vermelha. De forma que as peças mais densas e mais resistentes foram também as que apresentaram maior probabilidade de ocorrência de fratura. Elas são menos homogêneas quanto aos defeitos de fabricação, ou seja, são menos confiáveis. Isto indica que o parâmetro de Weibull está intrinsecamente relacionado ao tipo de microestrutura formada durante o processo de queima de cerâmica vermelha.

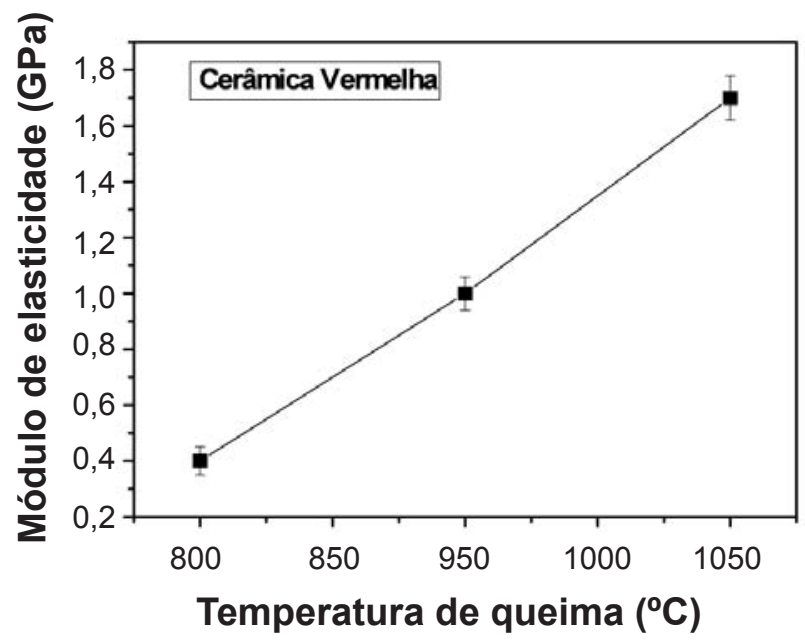

Figura 9: Módulo de elasticidade flexural em função da temperatura de queima.

[Figure 9: Elastic modulus as a function of the firing temperature.]

O módulo de elasticidade flexural das peças de cerâmica vermelha é apresentado na Fig. 9. O comportamento do módulo de elasticidade é fortemente dependente da temperatura de queima. O valor do módulo de elasticidade aumentou de 0,4 até $1,7 \mathrm{GPa}$, como um resultado do aumento do grau de sinterização. Esta variação no valor do módulo de elasticidade reflete fundamentalmente a evolução das fases presentes nas peças queimadas, dependendo da temperatura de queima. Em materiais multifásicos como a cerâmica vermelha, o módulo de elasticidade total corresponde a um valor intermediário dos valores de módulo de elasticidade das respectivas fases presentes. As peças de cerâmica vermelha quando queimadas até cerca de $950{ }^{\circ} \mathrm{C}$ são constituídas basicamente por uma matriz de material alumino-silicato amorfo (metacaulinita), partículas de quartzo, talvez uma pequena quantidade de filamentos de vidro e uma fase porosa em quantidade significativa. Isto explica os menores valores de módulo de elasticidade flexural obtidos nesta região de temperatura. Quando a temperatura foi aumentada para $1050{ }^{\circ} \mathrm{C}$ algumas mudanças químicas e físicas ocorreram. Nesta temperatura a vitrificação já está em curso, onde a fase líquida que se forma (filamentos de vidro) entra nos poros entre as partículas mais refratárias. O quartzo presente na argila tende a ser parcialmente dissolvido, e ocorre também o aparecimento de novas fases cristalinas tais como mullita primária e espinélio Al:Si (Fig. 3). Estes processos contribuem para a redução da porosidade, resultando num aumento significativo no valor de módulo de elasticidade flexural das peças de cerâmica vermelha.

\section{CONCLUSÕES}

$\mathrm{O}$ efeito da temperatura de queima foi o de produzir peças de cerâmica vermelha com propriedades mecânicas melhoradas. Isto se deve fundamentalmente ao fechamento da porosidade aberta no interior das peças de cerâmica vermelha. A porosidade aberta observada se deve principalmente a desidroxilação da caulinita (formação da metacaulinita amorfa) e posterior transformação para fases cerâmicas de alta temperatura (formação da mullita). Até cerca de $950^{\circ} \mathrm{C}$ ocorre fraca sinterização sólida das partículas associada à alta porosidade aberta, que tende a favorecer em termos de propriedades físico-mecânicas a produção de tijolos e blocos cerâmicos. Acima de $950{ }^{\circ} \mathrm{C}$ a porosidade aberta pode se fechar de forma mais significativa, devido provavelmente à presença de uma pequena quantidade de finos filamentos de vidro, que tende a favorecer a produção de telhas e tubos cerâmicos. Os dados experimentais de tensão de ruptura à flexão se ajustam de acordo com a distribuição de Weibull para as condições estudadas, bem como apresentaram um comportamento unimodal. Os parâmetros de Weibull obtidos de 8,59-12,42 estão compreendidos dentro da faixa esperada para materiais cerâmicos. Entretanto, o aumento da temperatura de queima tende a reduzir o parâmetro de Weibull de cerâmica vermelha.

\section{AGRADECIMENTOS}

Os autores agradecem ao CNPq pelo apoio financeiro.

\section{REFERÊNCIAS}

[1] Pólo Produções, Anuário Brasileiro de Cerâmica Vermelha, Ed. J. L. Francisco, Criciúma, SC (2000).

[2] J. V. Souza, P. S. Santos, Cerâmica 10, 38 (1964) 2.

[3] J. Rawet, P. S. Santos, Cerâmica 26, 128 (1980) 193.

[4] W. L. P. Correia, Cerâmica 33, 204 (1987) 27-46.

[5] R. S. Macedo, A. G. S. Galdino, C. R. S. Morais, H. C. Ferreira, Cerâmica 41, 275 (1996) 259.

[6] L. F. A. Campos, R. S. Macedo, P. K. Kiyohara, H. C. 
Ferreira, Cerâmica 45, 295 (1999) 140-145.

[7] J. Alexandre, F. Saboya, B. C. Marques, M. L. P. Ribeiro, C. Salles, M. G. Silva, M. S. Sthel, L. T. Auler, H. Vargas, The Analyst 124 (1999) 1209-1214.

[8] C. M. F. Vieira, J. N. F. Holanda, D. G. Pinatti, Cerâmica 46, 297 (2000) 15-18.

[9] A. P. F. Albers, F. G. Melchiades, R. Machado, J. B. Baldo, A. O. Boschi, Cerâmica 48, 305 (2002) 34-37.

[10] C. M. F. Vieira, S. N. Monteiro, Cerâmica 49, 309 (2003) 6-10.

[11] S. R. Teixeira, S. A. Souza, M. A. L. Nobre, Cerâmica 50, 315 (2004) 268-273.

[12] C. A. S. Pérez, D. Gobbi, J. L. N. Marcos, C. Paduani, J. D. Ardisson, Cerâmica 50, 314 (2004) 122-127.

[13] G. P. Souza, S. J. G. Sousa, L. A. H. Terrones, J. N. F. Holanda, Cerâmica 51, 320 (2005) 382-387.

[14] M. L. Varela, R. M. Nascimento, A. E. Martinelli, D. Hortza, D. M. A. Melo, M. A. F. Melo, Cerâmica 51, 320 (2005) 388-392.

[15] R. R. Menezes, H. S. Ferreira, G. A. Neves, H. C. Ferreira, Cerâmica 52, 321 (2006) 37-49.
[16] I. S. Ramos, J. Alexandre, M. G. Alves, V. Vogel, M. Gantos, Cerâmica 54, 331 (2008) 280-286.

[17] L. Mota, R. Toledo, F. A. L. Machado, J. N. F. Holanda, H. Vargas, R. T. Faria Jr., Appl. Clay Sci. 42 (2008) 168-174. [18] P. S. Santos, Ciência e tecnologia de argilas, V. 1, Ed. Edgard Blücher Ltda., S. Paulo, SP (1989).

[19] J. F. M. Motta, A. Zanerdo, M. C. Junior, Ceram. Ind. 6, 2 (2001) 28-37.

[20] M. Dondi, Int. Ceram. J. (2003) 55-59.

[21] Y. Matsuo, S. Kimura, Techno Japan 21, 3 (1988) 8-19.

[22] G. A. Quinn, Eng. Mat. Handbook: Ceramics and Glass - Strength and Proof Testing, ASM International, New York, EUA, 4 (1992) 590-593.

[23] F. P. Beer, R. Johnston Jr., Resistência dos materiais, Ed. Mc Grawhill, S. Paulo, SP (1992).

[24] S. F. Pracidelli, F. G. Melchiades, Ceram. Ind. 2, 01-02 (1997) 31-36.

[25] C. F. Gomes, Argilas - o que são e para que servem, Fundação Calouste Gulbenkian, Lisboa, Portugal (1988).

[26] E. D. Zanotto, A. R. Migliori Jr., Cerâmica 37 (1991) 11. (Rec.03/04/2009, Ac. 22/12/2009) 